\title{
Editorial
}

\section{Ciencia y resolución de problemáticas: nuestra apuesta}

http://dx.doi.org/10.14718/revfinanzpolitecon.2018.10.2 .1

\section{Hernán Felipe Trujillo Quintero*}

El propósito fundamental la revista Finanzas y Política Económica, ha sido el de mejorar cualitativa (en mayor medida) y cuantitativamente la discusión sobre dos asuntos necesarios y controversiales en las sociedades de mercado: por un lado, las finanzas en sus varios niveles, y en particular, en lo relacionado con los mercados de capitales y mercados financieros; por el otro, la política económica, especialmente en su aporte a la estabilización del producto y en los efectos en el crecimiento económico y desarrollo del país y la región.

Justamente, el éxito de un propósito puede colegirse del cumplimiento de sus preceptos o, lo que es lo mismo, en el nivel de impacto de la misión encomendada. Para el caso de la revista Finanzas y Política Económica es necesario tomar una fotografía del momento actual y analizar el nivel de impacto, para así saber enfrentar los retos venideros, en procura del mejoramiento continuo.

Así, el impacto de nuestra revista en estos diez años de existencia se puede analizar desde varias ópticas. Actualmente, la revista se encuentra incluida en las principales bases de datos de la región, destacándose la presencia en Scopus y Web of Science. El número de citaciones promedio de cada artículo allí publicado (según Google Scholar) asciende a 17 y el H5-index es $7^{1}$. Lo anterior ha sido confirmado por Colciencias, que en la Convocatoria 768 de 2016 nos ha categorizado en $\mathrm{B}$, dentro de las 246 revistas científicas más importantes en el país y una de las 20 que publica en ciencias económicas ${ }^{2}$. Sin lugar a dudas, vamos por el camino correcto.

Por supuesto que somos jóvenes, lo que nos permite mirar hacia el horizonte con humildad y entereza, pero con firmeza; aún es largo el camino y buscar la excelencia supone mejorar y fortalecer continuamente los lazos con las comunidades científicas; así también, seguir apostando por la rigurosidad a la hora de elegir los artículos con mayor calidad, sobre todo aquellos que aporten a la resolución de problemáticas en las áreas definidas por nuestra política editorial.

\footnotetext{
* Magíster en Ciencias en Desarrollo Sostenible, Tecnológico de Estudios Superiores de Monterrey, Atizapán de Zaragoza, México. Docente de la Universidad Católica de Colombia, Bogotá, Colombia. Coeditor de la revista Finanzas y Política Económica. Correo electrónico: hftrujillo@ucatolica.edu.co. https://orcid.org/00000002-3028-0125.

1 Ver en: https://scholar.google.com/citations?hl=en\&view_op=list_hcore\&venue=ExRIh8lofJIJ.2018

2 Para mayor información sobre los resultados de la convocatoria 768 de 2016, véase el siguiente vínculo: http://www.colciencias.gov.co/sites/default/files/listado-revistas-por-categoria-conv-768.pdf.
} 
Para el número que nos ocupa, encontramos ocho (8) artículos organizados así: cuatro (4) en el tema de finanzas, donde se analiza el impacto de la concentración de la propiedad accionaria en Chile y Colombia, así como los riesgos de liquidez y apalancamiento de empresas mexicanas y colombianas. Los últimos cuatro (4) tratan sobre política económica y resaltan la política monetaria en Colombia y México, al igual que la política petrolera en la estabilidad del ingreso colombiano.

De manera particular, en el primer artículo, Muñoz, Sepúlveda y Veloso analizan el impacto de las políticas de financiamiento, dividendos y de gobierno corporativo sobre la estructura de propiedad de las compañías chilenas; encuentran que las políticas de endeudamiento y de dividendos afectan negativamente la propiedad de los accionistas controladores y protegen los derechos de los accionistas minoritarios. Para el segundo artículo, Saavedra y Loé proponen una herramienta de control de efectivo para que los micro y pequeños empresarios del sector automotor y de tecnologías de la información puedan reducir los riesgos de liquidez en México. Por otra parte, Gil, Rosso y Ocampo, en el tercer artículo, determinan el efecto de la inestabilidad financiera en la estructura de capital de firmas de Colombia y Argentina; evidencian para ambos países que el menor nivel de liquidez y las pérdidas durante dos o más trimestres consecutivos elevan el nivel de apalancamiento de las firmas y las conduce al sobreendeudamiento. En el cuarto artículo, García analiza el efecto de la concentración de la propiedad accionaria en la liquidez de las acciones en el mercado bursátil en Colombia; halla que hay una relación inversa entre concentración de la propiedad y liquidez, con mayores impactos en la propiedad privada.

En el quinto artículo, Rosas y López analizan la relación entre inflación e incertidumbre inflacionaria en México, en el periodo 1969-2017, y corroboran así la hipótesis de Holland y de Friedman-Bal. En el sexto artículo, Cerquera, Marín y Polania revisan la relación entre el precio del petróleo y de la gasolina corriente en Colombia; sus hallazgos les permite concluir que los precios no tienen una relación directa por efectos exógenos. El séptimo artículo es una comparación de los proyectos de ley para redenominar la moneda colombiana en el siglo XXI; Alonso y Estrada encuentran que hay coincidencias entre ellos y los reagrupan entre los proyectos de redenominación permanente al nuevo peso y los que no, algo interesante para el debate coyuntural sobre el asunto. Por último, en el octavo artículo Candelo identifica la relación entre precio del petróleo y la tasa de cambio real en la economía del Valle del Cauca; encuentra que aumentos en el precio del petróleo generan efectos negativos y asimétricos en la estructura económica regional, mientras que aumentos en el tipo de cambio real generan efectos positivos.

Así las cosas, los aportes de la revista Finanzas y Política Económica seguirán teniendo impactos positivos en la comunidad académica, con contribuciones reales en las discusiones científicas y en la sociedad en general; de este modo se logrará canalizar la comprensión de nuestras realidades para mejorar nuestro bienestar. Esto justamente será nuestro mejor indicador de éxito, que redundará en mayor visibilidad e impacto; y para ello continuamos consolidando las buenas prácticas editoriales y científicas de la revista. 